\title{
Cruising: Impact Factor Data
}

\author{
Kenneth J. Zucker • James M. Cantor
}

Published online: 19 November 2009

(C) Springer Science+Business Media, LLC 2009

In this Editorial, we provide an update on the Journal's operations (Zucker \& Cantor, 2003, 2005, 2006, 2008).

\section{Submissions and Disposition}

Figure 1 shows the number of original submissions to the Journal between 2002 and 2008. In 2008, Archives crossed the 200 new submission barrier for the first time. At the time of penning this Editorial, the projected submission rate for 2009 is 235.

Figure 2 shows the Editorial decision data for the original submissions as a function of year (2002-2008). The percentage of manuscripts that were accepted or provisionally accepted ranged from 12.4 to $21.2 \%$; the percentage of manuscripts that were subject to major revision ranged from 33.9 to $47.5 \%$; and the percentage of manuscripts that were rejected ranged from 31.2 to $57.7 \%$. A 7 (year) $\times 3$ (decision) chi-square test was statistically significant, $\chi^{2}(12)=30.26, p<.01$. Visual inspection of Fig. 2 suggests that this was accounted for, in part, by the increase in the percentage of rejected submissions in 2008 and a decrease in the percentage of manuscripts that were in the major revision category. Interestingly, the percentage of accepted or

\section{K. J. Zucker $(\bowtie)$}

Gender Identity Service, Child, Youth, and Family Program, Centre for Addiction and Mental Health, 250 College Street,

Toronto, ON M5T 1R8, Canada

e-mail: Ken_Zucker@camh.net

J. M. Cantor

Law and Mental Health Program, Centre for Addiction and Mental

Health, Toronto, ON, Canada provisionally accepted manuscripts has not changed over this 7 -year period, $\chi^{2}(6)=6.21$, ns. Thus, the percentage of manuscripts that were accepted or provisionally accepted appears unrelated to the absolute increase in submission number.

An important question pertains to the fate of the manuscripts with an Editorial decision of "major revision" (revise and resubmit). As noted in our last Editorial (Zucker \& Cantor, 2008), about $50 \%$ of these manuscripts wind up being resubmitted to the Journal, and almost all of these are accepted for publication. The remaining $50 \%$ are not resubmitted to the Journal: They either wind up in the file drawer or in other periodicals, but we do not have data on their fate. More per se is not better; however, with the increase in submissions this means that the queue for publication is longer. This points to the importance of advance online publication, which has been operational now for several years. Interested readers can track papers that are online first ahead of print by simply typing the name of the journal when accessing PubMed or the Springer link to Archives. The Journal has accommodated the increased number of accepted manuscripts, in part, with an increase in allocated page numbers-1000 for 2009 (see also below).

\section{The Impact Factor}

Calculated each year by the Institute for Scientific Information (ISI), a journal's impact factor (IF) for a given year is a measure of the frequency with which its recent articles are cited on average during that year. "Recent" refers to the two prior calendar years. Thus, Archives' $2008 \mathrm{IF}$ is the number of times that its 2007 and 2006 articles were cited in 2008, divided by the number of articles the Archives published in 2006 and 2007. Although the IF is the best known metric for citation analysis, there are other measures, including the Immediacy Index (II) and the Cited Half-Life (CHL). The II 


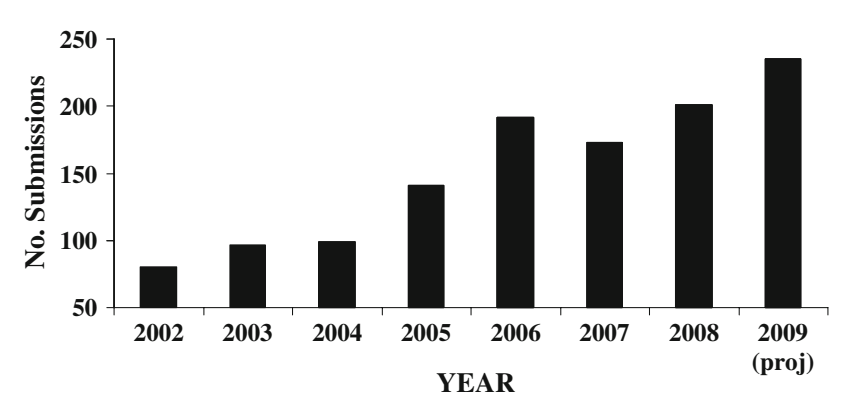

Fig. 1 Number of submissions (2002-2009)

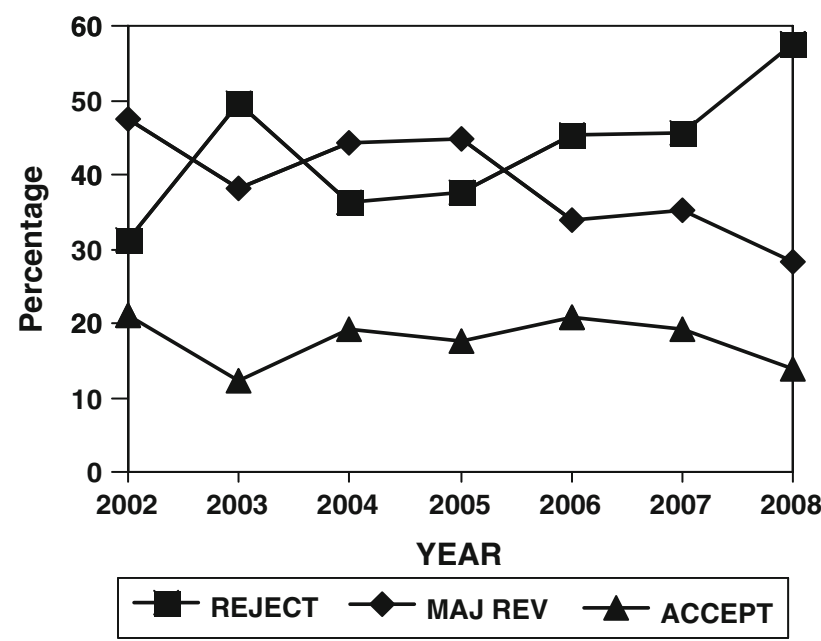

Fig. 2 Manuscript disposition after initial submission (2002-2008)

is a measure of how frequently the journal's "average article" is cited the same year in which it is published. Thus, the II for a year is calculated as the number of times articles from that journal are cited during that year, divided by the number of articles that journal published that year. The CHL is a measure of the longevity of the frequency of citations to articles in the journal, that is, for how long the average article maintains its currency. The CHL for a year is determined by the time required to account for a cumulative total of $50 \%$ of that year's citations to the journal.

Tables 1 and 2 show the IF of the sex and gender periodicals, broadly defined, for the years 2007 and 2008. For these two years, the Archives has shown a stable IF, surpassing the previous bests of 2.29 in 2004 and 2.19 in 2006. Hopefully, we are now on some kind of cruise control, but increased impact tumescence is welcomed (Fig. 3). For 2008, of 1,980 Social Science journals, Archives was ranked 212th (89th percentile) and, of 88 journals classified under Psychology (Clinical), Archives was ranked 21st (76th percentile). Starting next year, the Archives will also be classified under the Interdisciplinary category. Had it been classified under this category in 2008, it would have ranked 2nd out of 61 periodicals.

\section{Transitions}

In this final issue for 2009, the careful reader of the inside cover will detect some changes to the Editorial Board. Drs. Julia R. Heiman (1979-2009) and Cindy M. Meston (2002-2009) have stepped down from the Board. As many readers know, Dr. Heiman has been the Director of the Kinsey Institute for Research in Sex, Gender, and Reproduction at Indiana University since 2004, and her many responsibilities there have had, understandably, resulted in a reordering of priorities. Thirty years as a reviewer for Archives strikes us as a reasonable demonstration of commitment to the Journal's wellbeing. Of the current Board, only Peter M. Bentler has had a longer tenure. When the Journal first began publishing in 1971, there were 6 Associate Editors and 13 Editorial Board members. All were men. When Heiman joined the Board, she had been preceded by only 6 other women (Anke A. Ehrhardt, Evelyn Hooker, Diane S. Fordney-Settlage, Suzanne Chevalier-Skolnikoff, Georgiana Seegar Jones, and Phyllis A. Katz). The Board's current 2:1 ratio of men to women is, hopefully, a decent reflection of the contemporary gender balance among sexological researchers. Maybe Dylan had it right: "The times they are a-changin'."

With this issue, please welcome the appointment of 10 new members to the Board: José A. Bauermeister, Paul Enzlin, Melissa A. Farmer, Christian Grov, Tuuli M. Kukkonen, Robin Milhausen, David A. Moskowitz, Miguel Muñoz-Laboy, Nicole Prause, and Doug P. VanderLaan.

It is a pleasure to announce that, effective 2010, Dr. James M. Cantor has been appointed as Editor of Sexual Abuse: A Journal of Research and Treatment, and Dr. Jacques J. D. M. van Lankveld has been appointed as Editor of the Annual Review of Sex Research (which is now being published as a special issue of Journal of Sex Research).

Lastly, let us note that the publisher has authorized an increase in the number of published pages/volume. For 2010, the number of published pages will increase from 1000 to $1100+$. For this, we owe our continued thanks to Carol Bischoff at Springer for her steady commitment to the success of the Journal. 
Table 1 Impact factor for the year 2007: Sex- and gender-related journals $(N=45)$

\begin{tabular}{|c|c|c|c|c|c|}
\hline Journal & $\begin{array}{l}\text { Impact } \\
\text { factor }\end{array}$ & $\begin{array}{l}2007 \text { total } \\
\text { cites }\end{array}$ & $\begin{array}{l}2007 \\
\text { articles }\end{array}$ & $\begin{array}{l}\text { Immediacy } \\
\text { index }\end{array}$ & $\begin{array}{l}\text { Cited } \\
\text { half-life }\end{array}$ \\
\hline Archives of Sexual Behavior & 2.393 & 1644 & 65 & 0.723 & 7.8 \\
\hline Journal of Sexual Medicine & 6.199 & 1990 & 199 & 1.357 & 1.9 \\
\hline AIDS & 5.842 & 19479 & 437 & 1.133 & 5.5 \\
\hline Psychoneuroendocrinology & 4.442 & 4656 & 132 & 0.470 & 5.4 \\
\hline Menopause & 3.672 & 2108 & 122 & 1.344 & 3.6 \\
\hline Hormones and Behavior & 3.401 & 4334 & 156 & 0.494 & 5.6 \\
\hline Fertility and Sterility & 3.168 & 18567 & 376 & 0.694 & 7.1 \\
\hline International Journal of Andrology & 3.040 & 1767 & 62 & 0.581 & 6.5 \\
\hline Perspectives in Sexual and Reproductive Health & 2.933 & 499 & 22 & 0.182 & 3.6 \\
\hline Sexually Transmitted Diseases & 2.928 & 4039 & 177 & 0.571 & 5.7 \\
\hline Sexually Transmitted Infections & 2.616 & 2728 & 136 & 0.743 & 4.3 \\
\hline Evolution and Human Behavior & 2.529 & 1060 & 54 & 0.537 & 5.7 \\
\hline AIDS Patient Care and STDs & 2.400 & 1193 & 105 & 0.248 & 4.0 \\
\hline AIDS and Behavior & 2.310 & 986 & 119 & 0.378 & 3.9 \\
\hline International Journal of Impotence Research & 2.059 & 1902 & 88 & 0.523 & 5.0 \\
\hline Journal of Sex \& Marital Therapy & 1.902 & 1032 & 26 & 0.923 & 6.9 \\
\hline AIDS Care & 1.836 & 2299 & 191 & 0.277 & 5.3 \\
\hline Sexual Abuse: A Journal of Research and Treatment & 1.643 & 482 & 25 & 0.200 & 5.5 \\
\hline Journal of Women's Health & 1.522 & 865 & 130 & 0.092 & 3.7 \\
\hline Gender and Society & 1.400 & 1029 & 33 & 0.121 & 9.7 \\
\hline AIDS Education and Prevention & 1.359 & 1217 & 42 & 0.048 & 6.1 \\
\hline International Journal of STD and AIDS & 1.300 & 2212 & 214 & 0.173 & 5.2 \\
\hline Psychology of Women Quarterly & 1.253 & 1403 & 36 & 0.167 & $>10.0$ \\
\hline Journal of Sex Research & 1.246 & 1274 & 34 & 0.118 & 9.0 \\
\hline Culture, Health, and Sexuality & 1.236 & 281 & 41 & 0.073 & 4.3 \\
\hline Journal of Psychosomatic Obstetrics and Gynecology & 0.951 & 627 & 21 & 0.095 & 9.2 \\
\hline GLQ: A Journal of Gay and Lesbian Studies & 0.778 & 159 & 20 & 0.050 & $>10.0$ \\
\hline Gender and Education & 0.743 & 370 & 40 & 0.075 & 6.9 \\
\hline European Journal of Women's Studies & 0.698 & 98 & 18 & 0.056 & - \\
\hline Signs & 0.671 & 730 & 40 & 0.075 & $>10.0$ \\
\hline Sex Roles & 0.652 & 2670 & 159 & 0.050 & 9.8 \\
\hline International Journal of Fertility and Women's Medicine & 0.556 & 216 & 4 & 0.000 & 5.9 \\
\hline Journal of Gender Studies & 0.441 & 77 & 17 & 0.000 & - \\
\hline Feminism and Psychology & 0.429 & 263 & 39 & 0.205 & 7.1 \\
\hline Women's Studies International Forum & 0.380 & 380 & 42 & 0.024 & 7.4 \\
\hline Asian Journal of Women's Studies & 0.360 & 20 & 14 & 0.000 & - \\
\hline Sexuality and Disability & 0.275 & 181 & 24 & 0.000 & 8.3 \\
\hline Australian Feminist Studies & 0.213 & 78 & 25 & 0.080 & - \\
\hline Journal of the History of Sexuality & 0.194 & 86 & 17 & 0.000 & $>10.0$ \\
\hline Journal of Homosexuality & 0.159 & 598 & 33 & 0.000 & $>10.0$ \\
\hline Feminist Review & 0.129 & 181 & 27 & 0.000 & $>10.0$ \\
\hline Frontiers: Journal of Women's Studies & 0.118 & 52 & 19 & 0.000 & - \\
\hline Women and Therapy & 0.080 & 134 & 21 & 0.000 & $>10.0$ \\
\hline Feminist Studies & 0.078 & 246 & 13 & 0.000 & $>10.0$ \\
\hline Sexual Development & N/A & 14 & 38 & 0.342 & - \\
\hline
\end{tabular}

Note: Total Cites means the number of references cited in the articles published in the journal in 2007. Immediacy Index means cites in 2007 to articles published in 2007/number of articles published in 2007. Cited half-life is the median age of its articles cited in the current year. Half of the citations to the journal are to articles published within the cited half-life 
Table 2 Impact factor for the year 2008: Sex- and gender-related journals $(N=47)$

\begin{tabular}{|c|c|c|c|c|c|}
\hline Journal & $\begin{array}{l}\text { Impact } \\
\text { factor }\end{array}$ & $\begin{array}{l}2008 \text { total } \\
\text { cites }\end{array}$ & $\begin{array}{l}2008 \\
\text { articles }\end{array}$ & $\begin{array}{l}\text { Immediacy } \\
\text { index }\end{array}$ & $\begin{array}{l}\text { Cited } \\
\text { half-life }\end{array}$ \\
\hline Archives of Sexual Behavior & 2.300 & 2015 & 73 & 0.712 & 7.6 \\
\hline AIDS & 5.460 & 20159 & 353 & 1.309 & 5.7 \\
\hline Journal of Sexual Medicine & 5.393 & 2803 & 317 & 0.678 & 2.3 \\
\hline Perspectives in Sexual and Reproductive Health & 4.533 & 758 & 28 & 0.286 & 4.4 \\
\hline Fertility and Sterility & 4.167 & 21960 & 573 & 0.663 & 7.2 \\
\hline International Journal of Andrology & 4.021 & 2052 & 70 & 0.986 & 6.0 \\
\hline Hormones and Behavior & 3.876 & 5638 & 170 & 0.718 & 5.7 \\
\hline Psychoneuroendocrinology & 3.788 & 5521 & 146 & 0.418 & 5.7 \\
\hline Menopause & 3.452 & 2223 & 157 & 0.783 & 3.7 \\
\hline AIDS Reviews & 3.268 & 489 & 21 & 0.333 & 4.3 \\
\hline Sexually Transmitted Diseases & 2.863 & 4677 & 182 & 0.791 & 5.8 \\
\hline AIDS and Behavior & 2.729 & 1388 & 117 & 0.513 & 3.4 \\
\hline Evolution and Human Behavior & 2.584 & 1376 & 52 & 0.596 & 5.7 \\
\hline Sexually Transmitted Infections & 2.571 & 3152 & 150 & 0.760 & 4.7 \\
\hline AIDS Patient Care and STDs & 2.392 & 1489 & 97 & 0.309 & 4.1 \\
\hline International Journal of Impotence Research & 2.276 & 2151 & 88 & 0.534 & 5.1 \\
\hline Journal of Sex \& Marital Therapy & 2.214 & 1272 & 27 & 0.519 & 7.1 \\
\hline Journal of Women's Health & 1.943 & 1214 & 153 & 0.124 & 3.8 \\
\hline Psychology of Women Quarterly & 1.671 & 1591 & 38 & 0.184 & $>10.0$ \\
\hline Journal of Psychosomatic Obstetrics and Gynecology & 1.585 & 729 & 37 & 0.027 & 8.1 \\
\hline AIDS Education and Prevention & 1.505 & 1228 & 43 & 0.116 & 6.4 \\
\hline AIDS Care & 1.466 & 2601 & 167 & 0.168 & 5.5 \\
\hline Gender and Society & 1.387 & 1322 & 29 & 0.655 & 10.0 \\
\hline Journal of Sex Research & 1.373 & 1462 & 33 & 0.091 & 9.0 \\
\hline Culture, Health, and Sexuality & 1.367 & 377 & 62 & 0.194 & 3.8 \\
\hline Gender, Place, and Culture & 1.165 & 482 & 31 & 0.129 & 6.4 \\
\hline Sexual Abuse: A Journal of Research and Treatment ${ }^{\mathrm{a}}$ & 1.151 & 472 & N/A & N/A & 6.1 \\
\hline European Journal of Women's Studies & 1.139 & 132 & 20 & 0.150 & 4.5 \\
\hline International Journal of STD and AIDS & 1.075 & 2389 & 224 & 0.246 & 5.8 \\
\hline Sexual Development & 1.000 & 45 & 26 & 0.231 & \\
\hline Women \& Health & 0.941 & 1229 & 47 & 0.085 & 8.2 \\
\hline Gender and Education & 0.782 & 356 & 38 & 0.079 & 6.5 \\
\hline Sex Roles & 0.743 & 3226 & 147 & 0.150 & 9.8 \\
\hline Journal of Homosexuality & 0.590 & 827 & 54 & 0.148 & $>10.0$ \\
\hline Feminism and Psychology & 0.569 & 287 & 33 & 0.030 & 7.1 \\
\hline GLQ: A Journal of Gay and Lesbian Studies & 0.487 & 163 & 32 & 0.094 & 6.8 \\
\hline Feminist Review & 0.407 & 209 & 24 & 0.000 & $>10.0$ \\
\hline Journal of Gender Studies & 0.394 & 83 & 25 & 0.120 & \\
\hline Women's Studies International Forum & 0.394 & 441 & 48 & 0.021 & 8.6 \\
\hline Signs & 0.356 & 872 & 59 & 0.017 & $>10.0$ \\
\hline Sexuality and Disability & 0.311 & 185 & 21 & 0.000 & 8.6 \\
\hline Women and Therapy & 0.222 & 192 & 20 & 0.000 & $>10.0$ \\
\hline Feminist Studies & 0.184 & 306 & 24 & 0.000 & $>10.0$ \\
\hline Australian Feminist Studies & 0.167 & 75 & 35 & 0.143 & \\
\hline
\end{tabular}


Table 2 continued

\begin{tabular}{llcccc}
\hline Journal & $\begin{array}{l}\text { Impact } \\
\text { factor }\end{array}$ & $\begin{array}{l}2008 \text { total } \\
\text { cites }\end{array}$ & $\begin{array}{l}\text { 2008 } \\
\text { articles }\end{array}$ & $\begin{array}{l}\text { Immediacy } \\
\text { index }\end{array}$ & $\begin{array}{l}\text { Cited } \\
\text { half-life }\end{array}$ \\
\hline Frontiers: Journal of Women's Studies & 0.158 & 86 & 14 & 0.071 & 0.000 \\
Asian Journal of Women's Studies & 0.154 & 35 & 17 & 15 & 0.133 \\
Journal of the History of Sexuality & 0.062 & 111 & 15 & 8.7 \\
\hline
\end{tabular}

Note: Total Cites means the number of references cited in the articles published in the journal in 2008. Immediacy Index means cites in 2008 to articles published in 2008/number of articles published in 2008. Cited half-life is the median age of its articles cited in the current year. Half of the citations to the journal are to articles published within the cited half-life

a The Impact Factor appears to be artificially low due "to the late arrival of journal issues published within 2008" to the ISI Web of Knowledge database, likely a result in a change of publisher (e-letter from C. Allmon to J. Cantor, July 6, 2009). An attempt to calculate the IF by hand using the ISI database suggests an actual impact factor of 1.623 (e-letter from J. Cantor to K. J. Zucker, July 22, 2009)

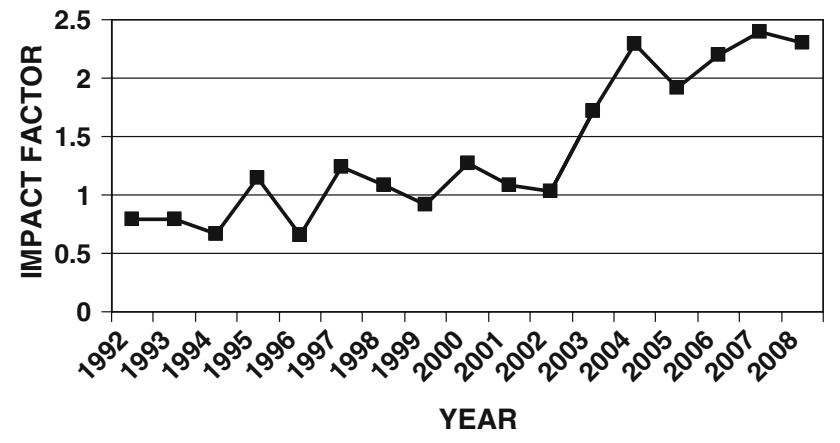

Fig. 3 Impact factor (1992-2008)

\section{References}

Zucker, K. J., \& Cantor, J. M. (2003). The numbers game: The impact factor and all that jazz [Editorial]. Archives of Sexual Behavior, 32, $3-5$.

Zucker, K. J., \& Cantor, J. M. (2005). The impact factor: "Goin' up" [Editorial]. Archives of Sexual Behavior, 34, 7-9.

Zucker, K. J., \& Cantor, J. M. (2006). The impact factor: The Archives breaks from the pack [Editorial]. Archives of Sexual Behavior, 35, 7-9.

Zucker, K. J., \& Cantor, J. M. (2008). The Archives in the era of online first ahead of print [Editorial]. Archives of Sexual Behavior, 37, 512-516. 